\title{
Ligand Recognition Determines the Role of Inhibitory B Cell Co-receptors in the Regulation of B Cell Homeostasis and Autoimmunity
}

\author{
Takeshi Tsubata* \\ Department of Immunology, Medical Research Institute, Tokyo Medical and Dental University, Tokyo, Japan
}

B cells express various inhibitory co-receptors including CD22, CD72, and Siglec-G. These receptors contain immunoreceptor tyrosine-based inhibition motifs (ITIMs) in the cytoplasmic region. Although many of the inhibitory co-receptors negatively regulate BCR signaling by activating $\mathrm{SH}$-containing protein tyrosine phosphatase 1 (SHP-1), different inhibitory co-receptors have distinct functional properties. CD22, Siglec-G, and CD72 preferentially regulate tonic signaling in conventional B cells, B-1 cell homeostasis, and development of lupus-like disease, respectively. CD72 recognizes RNA-related lupus self-antigen Sm/RNP as a ligand. This ligand recognition recruits CD72 to BCR in

OPEN ACCESS

Edited by:

Aaron James Marshall,

University of Manitoba, Canada

Reviewed by:

Pablo Engel,

University of Barcelona, Spain

Louis Justement,

University of Alabama at Birmingham,

United States

*Correspondence:

Takeshi Tsubata

tsubata.imm@mri.tmd.ac.jp

Specialty section:

This article was submitted to

B Cell Biology,

a section of the journal

Frontiers in Immunology

Received: 02 July 2018 Accepted: 13 September 2018

Published: 02 October 2018

Citation:

Tsubata T (2018) Ligand Recognition

Determines the Role of Inhibitory $B$ Cell Co-receptors in the Regulation of

$B$ Cell Homeostasis and

Autoimmunity.

Front. Immunol. 9:2276.

doi: 10.3389/fimmu.2018.02276
$\mathrm{Sm} / \mathrm{RNP}$-reactive B cells thereby suppressing production of anti-Sm/RNP autoantibody involved in the pathogenesis of lupus. In contrast, Siglec-G recognizes $\alpha 2,3$ as well as $\alpha 2,6$ sialic acids whereas CD22 recognizes $\alpha 2,6$ sialic acid alone. Because glycoproteins including BCR are dominantly glycosylated with $\alpha 2,3$ sialic acids in B-1 cells, Siglec-G but not CD22 recruits BCR as a ligand specifically in B-1 cells, and regulates B-1 cell homeostasis by suppressing BCR signaling in B-1 cells. Thus, recognition of distinct ligands determines functional properties of different inhibitory B cell co-receptors.

Keywords: inhibitory B cell co-receptor, CD72, CD22, siglec-G, systemic lupus erythematosus, B-1 cells, Sm/RNP, sialic acid

\section{INTRODUCTION}

Antigen-induced signaling through $\mathrm{B}$ cell receptor (BCR) plays a central role in B cell responses to antigens (1). BCR also transmits constitutive low level signaling called tonic signaling in the absence of antigen stimulation (2). Tonic signaling regulates B cell survival and development. BCR ligation activates protein tyrosine kinases such as Lyn and Syk, which phosphorylate and activate various down-stream signaling molecules (1). BCR signaling is negatively regulated by various inhibitory co-receptors such as Fc $\gamma$ RIIB, Sialic acid-binding Ig-like lectin (Siglec)10/G (human/mouse ortholog), CD22 (also known as Siglec-2), CD72, PECAM1 (also known as CD31), CEACAM-1, and LILRB/PIR-B (human/mouse ortholog) $(3,4)$. These inhibitory coreceptors contain immunoreceptor tyrosine-based inhibition motifs (ITIMs) in the cytoplasmic region. ITIMs in Fc $\gamma$ RIIB and CD22 are shown to be phosphorylated by Lyn when BCR is ligated. Lyn may also be responsible for phosphorylation of the ITIMs in the other inhibitory coreceptors. Upon phosphorylation, these ITIMs recruit and activate SH2-containing phosphatases such as $\mathrm{SH} 2$-containing protein tyrosine phosphatase (SHP)-1, SHP-2, and SH2-containing inositol $5^{\prime}$-phosphatase (SHIP)-1, thereby down-modulating BCR signaling by dephosphorylating signaling 
molecules activated by BCR ligation (Figure 1). SHIP-1 negatively regulates phosphatidyl inositol 3-kinase (PI-3K)Akt pathway by dephosphorylating PIP3 generated by PI-3K (5). Studies on B cells deficient in SHP-1 or inhibitory coreceptors demonstrated that proximal signaling molecules of BCR including Lyn, Syk, Ig $\alpha / \operatorname{Ig} \beta$, BLNK/SLP-65 are hyperphosphorylated $(6,7)$. Because SHP-1 associates with Lyn (8) and Syk (9), these kinases appear to be substrates of SHP-1. The other BCR signaling molecules may be directly or indirectly dephosphorylated by SHP-1. It may be unlikely that SHP-1 activated by different co-receptors dephosphorylate distinct substrates though there is no evidence. CD22 was reported to recruit stimulatory signaling molecules including Syk and phospholipase $C \gamma(10)$. However, SHP-1 appears to be the dominant effector of CD22 because CD22 negatively regulates BCR signaling.

Fc $\gamma$ RIIB recruits SHIP-1 but not SHP-1 or SHP-2 at phosphorylated ITIMs whereas the other inhibitory $\mathrm{B}$ cell co-receptors recruit SHP-1, SHP-2 or both (3). Although the sequence of ITIMs may determine which phosphatase is recruited, the precise mechanism is not yet clear. Although the roles of SHP-2 in B cells is not yet clear, SHP-1 is shown to play crucial roles in the maintenance of $\mathrm{B}$ cell homeostasis. $\mathrm{B}$ cell-specific conditional SHP-1 $1^{-/}$mice show alterations in the development of conventional B cells, expansion of B-1 cells and development of lupus-like autoimmune disease (11) (Table 1). B cell-specific SHIP-1-deficient mice show similar phenotypes (12). However, Fc $\gamma \mathrm{RIIB}^{-/-}$mice show none of these phenotypes
(13) although FcyRIIB down-regulates antibody responses and is associated with autoimmune diseases (14). How SHIP-1 is activated to regulate development and homeostasis of $\mathrm{B}$ cells is not yet clear. In contrast, deficiency in SHP-1-activating coreceptors $\mathrm{CD} 22$, Siglec-G and CD72 causes alterations in the development of conventional B cells $(11,15-18)$, expansion of B-1 cells (19), and development of lupus-like disease $(20,21)$, respectively. Thus, SHP-1 activated by different co-receptors regulates distinct $\mathrm{B}$ cell phenotypes. Because the roles of the ligands are extensively studied in CD22, Siglec-G, and CD72 among SHP-1-activating B cell co-receptors, I would like to discuss distinct functional properties of different inhibitory coreceptors and the role of ligand recognition in determining their functional properties by focusing on CD22, Siglec-G and CD72.

\section{DISTINCT FUNCTIONAL PROPERTIES OF CD22, SIGLEC-G, AND CD72}

In Siglec-G $\mathrm{G}^{-/-}$mice, the number of B-1 cells in the peritoneal cavity is increased by around 10-folds (19), which is almost equivalent to B-1 cell expansion observed in B cell-specific SHP- $1^{-/-}$mice (11). In contrast, $\operatorname{CD} 22^{-/-}$mice $(15,16)$, PECAM $^{-/-}$mice (22), and PIR-B ${ }^{-/-}$mice (23) show only modest increase in the number of B-1 cells. Thus, Siglec-G plays a central role in SHP-1-mediated regulation of B-1 cells, whereas other inhibitory co-receptors play an auxiliary or no role in the regulation of B-1 cell homeostasis.

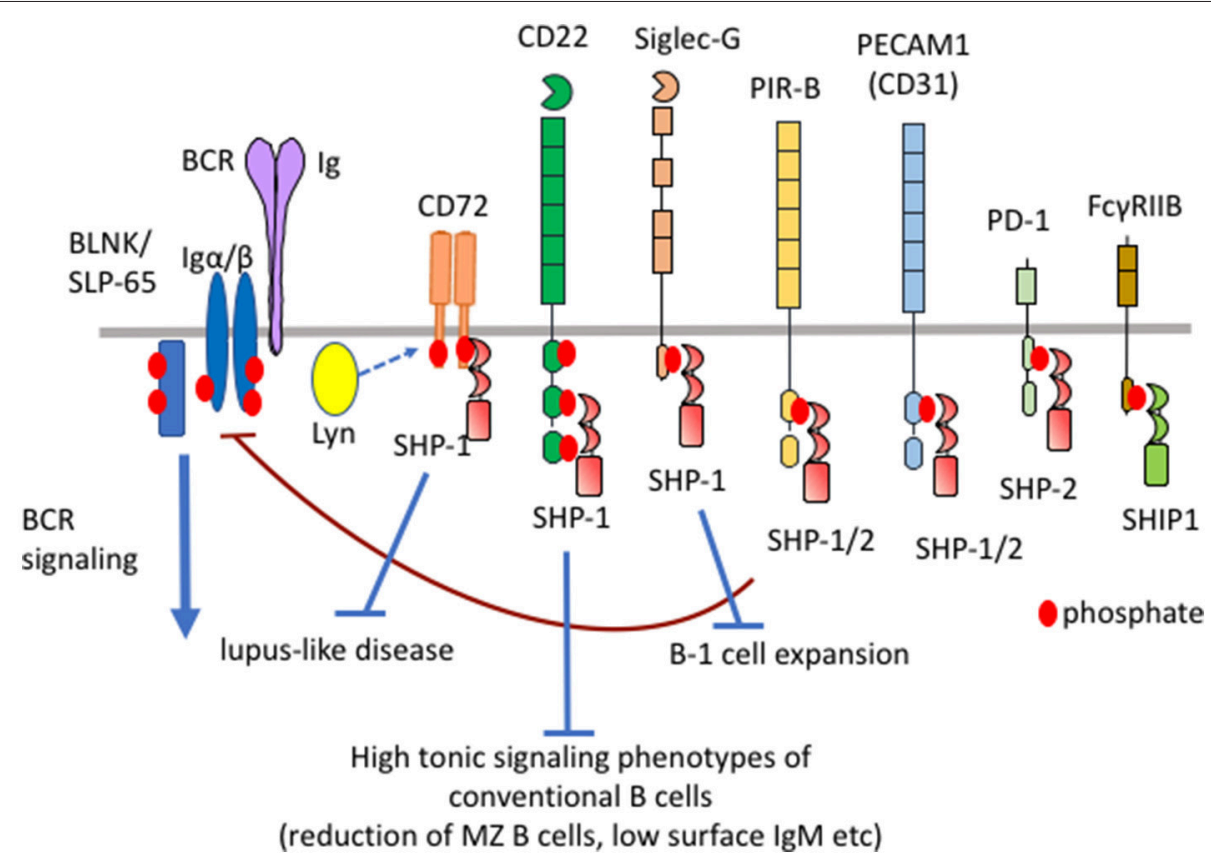

FIGURE 1 | Differential functional properties of inhibitory B cell co-receptors. Mouse B cells express various inhibitory co-receptors such as CD72, CD22, Siglec-G, PIR-B, PEACAM1, PD-1, and FC $\gamma$ RIIB. These receptors contain ITIMs in the cytoplasmic region and recruit SH2-containing phosphatases such as SHP-1, SHP-2, and SHIP-1 upon phosphorylation by Lyn, leading to down-modulation of BCR signaling. Although many of these inhibitory receptors activate SHP-1, CD72, CD22, and Siglec-G inhibits development of lupus-like disease, high tonic signaling phenotypes of conventional B cells, and B-1 cell expansion, respectively. 
TABLE 1 | B cell phenotypes of mice deficient in inhibitory B cell co-receptors, ligands, and effector phosphatases.

\begin{tabular}{|c|c|c|c|c|c|c|c|}
\hline \multirow[b]{2}{*}{ Phenotype $^{a}$} & \multicolumn{7}{|c|}{ Mice } \\
\hline & SHP-1-/- & SHIP-1-/- & $\mathrm{CD}^{2} 2^{-/-}$ & $\mathrm{CD}^{2} 2^{-/-}$ & Siglec-G ${ }^{-/-}$ & Siglec-G R120E ${ }^{b}$ & Fc $\gamma R$ RIIB \\
\hline High tonic signaling in conventional B cells ${ }^{\mathrm{C}}$ & ++ & ++ & ++ & - & - & - & - \\
\hline B-1 cell expansion & ++ & ++ & \pm & - & ++ & ++ & - \\
\hline Lupus-like disease & ++ & ++ & - & ++ & - & $\mathrm{NA}^{\mathrm{d}}$ & - \\
\hline
\end{tabular}

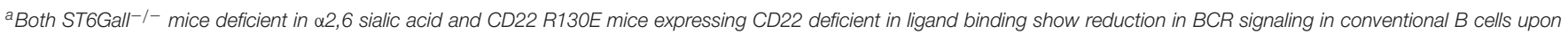
BCR ligation.

${ }^{b}$ Deficient in ligand binding.

${ }^{c}$ Reduction in marginal zone B cell population and reduction in the level of cell surface IgM.

${ }^{d}$ Not available.

$\mathrm{CD} 22^{-/-}$mice as well as B cell-specific SHP1-/- or $\mathrm{Lyn}^{-/-}$ mice show various alterations in conventional $\mathrm{B}$ cells such as reduction in the number of marginal zone (MZ) B cells and reduction in the level of IgM on the surface of follicular B cells $(11,15-18)$. Recently, Yasuda et al. demonstrated that IgM ${ }^{\text {hi }}$ cells show higher phosphorylation levels of signaling molecules such as Erk and Akt, and better in vitro survival compared to IgM ${ }^{\text {lo }}$ cells (24), suggesting that the total tonic signaling level required for B cell survival depends on the expression level of BCR. If BCR carries high tonic signaling activity, total tonic signaling level in $\mathrm{IgM}^{\mathrm{lo}}$ cells may be sufficient for survival. Thus, the reduction in the level of surface IgM in CD22-/- B cells suggests increased tonic signaling activity in the absence of CD22. This notion is also supported by the reduction in MZ B cells in CD22-/mice because $B$ cells with low tonic signaling are suggested to preferentially differentiate to MZ B cells (25). In contrast, these alterations in conventional $\mathrm{B}$ cells are not observed in mice deficient in other inhibitory co-receptors such as CD72.

Almost all $\mathrm{CD} 72^{-/-}$mice spontaneously develop lupus-like glomerulonephritis by 6 months of age (21). CD72-/- Fas ${ }^{\mathrm{lpr} / \mathrm{lpr}}$ mice on the C57BL/6 background develop severe lupus-like disease comparable to MRL.Fas ${ }^{\mathrm{lpr}}$ mice. Both CD72 $2^{-/-}$Fas ${ }^{\mathrm{lpr} / \mathrm{lpr}}$ mice and MRL.Fas ${ }^{\mathrm{lpr}}$ mice produce large amounts of autoantibodies such as anti-DNA antibody and develop glomerulonephritis with severe histological changes at 6 months of age. In contrast, mice deficient in other inhibitory coreceptors such as $\mathrm{CD} 22^{-/-}$mice and $\mathrm{PIR}-\mathrm{B}^{-/-}$mice do not develop autoimmune disease $(26,27)$. Even by introduction of Fas ${ }^{\mathrm{lpr}}$, only a fraction of PIR-B ${ }^{-/}-\mathrm{Fas}^{\mathrm{lpr} / \mathrm{lpr}}$ mice develop lupus-like disease at 12 months of age (27). Only a fraction of PECAM $^{-/-}$mice and Siglec-G ${ }^{-/-}$mice develop mild lupusline disease after 12 months of age $(22,26)$. Because development of autoimmune disease partly depends on the cleanness of the animal facility, it is not possible to discuss small differences in the disease severity among the different mice housed in different facilities. Nonetheless, CD72-/- mice develop lupus-like disease that is clearly more severe than that developed in mice deficient in other inhibitory co-receptors. Thus, CD72 appears to be a dominant inhibitory $\mathrm{B}$ cell co-receptor in the regulation of autoimmune disease.

Taken together, Siglec-G, CD22, and CD72 regulate B1 cell homeostasis, tonic signaling of conventional B cells, and development of lupus-like disease, respectively (Figure 1;
Table 1), suggesting that different inhibitory B cell co-receptors regulate distinct $\mathrm{B}$ cell phenotypes.

\section{ROLE OF LIGANDS IN DETERMINING FUNCTIONAL PROPERTIES OF INHIBITORY B CELL CO-RECEPTORS}

Most of the inhibitory co-receptors recognize endogenous ligands (Table 2). Role of the endogenous ligands in determining the functional properties of inhibitory co-receptors was first demonstrated in Fc $\gamma$ RIIB already in 1990s. Fc $\gamma$ RIIB inhibits BCR signaling when co-ligated with BCR. Binding of immune complexes composed of antigens and IgG with BCR induces co-ligation of Fc $\gamma$ RIIB and BCR, thereby down-regulating BCR signaling and antibody responses to the antigens $(28,29)$. In contrast, roles of endogenous ligands of SHP-1-activating inhibitory B cell co-receptors were not clear until a few years ago.

CD72 is a type II membrane molecule containing a C-type lectin-like domain (CTLD) in the extracellular region. The ligand of CD72 was initially reported to be CD5, although this result has not been reproduced (30). Later, CD100 (also known as Semaphorin-4D) was shown to be an inhibitory ligand of CD72 (31). The functional significance of this inhibitory ligand is not yet clear. We demonstrated that the extracellular CTLD of CD72 specifically recognizes the lupus self-antigen Sm/RNP as a ligand (32). Sm/RNP is a major RNA-containing lupus self-antigen, and a ligand of the endosomal RNA sensor TLR7 (33). Because TLR7 but not the DNA sensor TLR9 is essential for development of lupus-like disease in multiple mouse models (34), autoimmune response to RNA-related self-antigens such as Sm/RNP appears to be crucial in development of SLE.

When BCR is ligated by Sm/RNP, CD72-/- B cells show augmented $\mathrm{Ca}^{2+}$ and proliferative responses compared to $\mathrm{CD} 72^{+/+} \mathrm{B}$ cells $(32)$. In contrast, $\mathrm{Ca}^{2+}$ and proliferative responses to a control antigen in $\mathrm{CD} 72^{-/-} \mathrm{B}$ cells are comparable to that in $\mathrm{CD} 72^{+/+} \mathrm{B}$ cells. This result suggests that CD72 specifically down-regulates BCR signaling when BCR is ligated by $\mathrm{Sm} / \mathrm{RNP}$. When Sm/RNP binds to BCR expressed on the surface of Sm/RNP-reactive B cells, CD72 appears to be recruited to BCR because of its binding to Sm/RNP (Figure 2A). Antigenmediated recruitment of CD72 to Sm/RNP-reactive BCR may 
TABLE 2 | Inhibitory co-receptors and their ligands.

\begin{tabular}{|c|c|c|c|c|}
\hline $\begin{array}{l}\text { Inhibitory } \\
\text { co-receptors }\end{array}$ & Expression & Ligands & Role of ligands ${ }^{a}$ & Expression of ligands \\
\hline CD22 & Constitutive & $\alpha 2,6$ sialic acid & Inhibitory & Ubiquitous \\
\hline \multirow[t]{2}{*}{ CD72 } & Constitutive & Sm/RNP & Stimulatory & Released from dead cells \\
\hline & & CD100 (Sema4D) & Inhibitory & Various hematopoietic and non-hematopoietic cells \\
\hline \multirow[t]{2}{*}{ Siglec-G } & Constitutive & $\alpha 2,3$ sialic acid & Stimulatory & $\begin{array}{l}\text { Ubiquitous, } \\
\text { B1 cells }>>\text { conventional B cells }\end{array}$ \\
\hline & & $\alpha 2,6$ sialic acid & Stimulatory & Ubiquitous \\
\hline PIA-B & Constitutive & $\mathrm{MHCl}$ & Stimulatory & Ubiquitous \\
\hline \multirow[t]{2}{*}{ PECAM1 } & Constitutive & PECAM1 & $?$ & Endothelial cells, hematopoietic cells \\
\hline & & a2,6 sialic acid & $?$ & Ubiquitous \\
\hline \multirow[t]{2}{*}{ PD-1 } & Inducible & PD-L1 & Stimulatory & Hematopoietic cells, various non-hematopoietic cells \\
\hline & & PD-L2 & Stimulatory & Macrophages, DCs, mast cells, B-1 cells \\
\hline$F_{C \gamma} R \| B$ & Constitutive & $\lg G$ & Stimulatory & \\
\hline
\end{tabular}

a Inhibitory or stimulatory role in co-receptor-mediated signal inhibition.

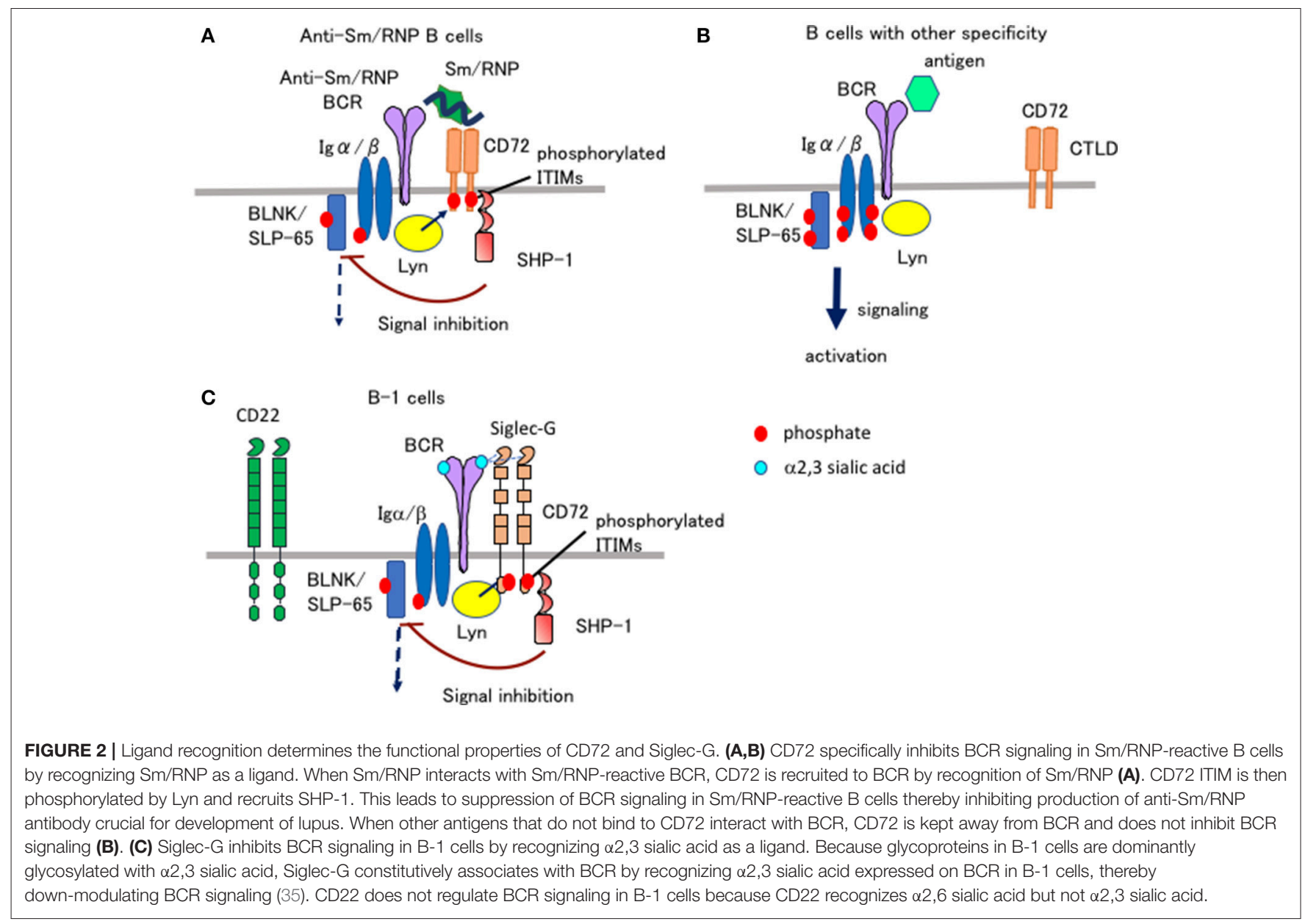

induce phosphorylation of the CD72 ITIM by BCR-associated Lyn, leading to SHP-1-mediated suppression of BCR signaling. In contrast, CD72 may not be recruited to BCR when BCR interacts with the other antigens that do not bind to CD72 (Figure 2B). Thus, CD72 negatively regulates BCR signaling induced by
Sm/RNP but not the other antigens, thereby specifically inhibits activation of $\mathrm{B}$ cells reactive to Sm/RNP. In $\mathrm{CD} 72^{-/-}$mice, $\mathrm{Sm} / \mathrm{RNP}$ activates $\mathrm{B}$ cells reactive to $\mathrm{Sm} / \mathrm{RNP}$ probably by inducing both BCR signaling and TLR7 signaling, leading to the production of anti-Sm/RNP antibody crucial for development 
of lupus. CD72 appears to inhibit development of lupus by inhibiting activation of Sm/RNP-reactive B cells.

Both CD22 and Siglec-G are members of the Siglec family, and recognize sialic acids as a ligand (36). CD22 specifically recognizes $\alpha 2,6$ sialic acid, whereas Siglec- $G$ broadly recognizes both $\alpha 2,3$ and $\alpha 2,6$ sialic acids. Previously, Nitschke and his collaborators addressed how Siglec-G but not CD22 strongly regulates BCR signaling in B-1 cells and B-1 cell homeostasis (35), although both Siglec-G and CD22 are expressed by both B-1 cells. They demonstrated that the Siglec-G mutant deficient in ligand binding no longer associates with $\mathrm{BCR}$ nor downregulates BCR signaling, suggesting that Siglec- $G$ associates with $B C R$ by recognizing sialic acid located in BCR thereby inhibiting BCR signaling. They further demonstrated that B-1 cells express $\alpha 2,3$ sialic acid at much higher level than conventional B cells. Recognition of $\alpha 2,3$ sialic acid by Siglec-G induces association of Siglec-G and BCR specifically in B-1 cells, which may induce phosphorylation of the Siglec-G ITIM by Lyn and activation of SHP-1 required for inhibition of BCR signaling (Figure 2C).

Although CD22 regulates tonic signaling, how ligand recognition of $\mathrm{CD} 22$ is involved in this function is not yet clear. As is the case for Siglec-G in B-1 cells, CD22 is shown to be associated with BCR by recognizing a sialylated ligand in conventional B cells (37). However, studies with mice deficient in ST6GalI, the sialyl transferase required for the synthesis of $\alpha 2,6$ sialic acid, and those with mice expressing a mutant CD22 that do not recognize $\alpha 2,6$ sialic acid showed that endogenous ligands rather down-modulate suppressive activity of CD22 (38-40). These findings are contradictory to the model in which ligand recognition induces CD22-mediated signal inhibition. Whether ligand recognition is involved in the functional properties of CD22 needs to be further studied. Other inhibitory co-receptors also recognize endogenous ligands (3). PIR-B is known to interact with MHC I (41). Because PIR-B phosphorylation is modestly reduced in $\beta 2 \mathrm{~m}^{-/-}$splenocytes (42), interaction of PIR-B with MHC-I may facilitate PIR-B-mediated signal inhibition. PECAM1 and CEACAM-1 (4) show homotypic interaction with trans-ligands, and PECAM1 was also shown to

\section{REFERENCES}

1. Kurosaki T, Shinohara H, Baba Y. B cell signaling and fate decision. Annu Rev Immunol. (2010) 28:21-55. doi: 10.1146/annurev.immunol.021908.132541

2. Myers DR, Zikherman J, Roose JP. Tonic signals: why do lymphocytes bother? Trends Immunol. (2017) 38:844-57. doi: 10.1016/j.it.2017.06.010

3. Tsubata T. Role of inhibitory BCR co-receptors in immunity. Infect Disord Drug Targets (2012) 12:181-90. doi: 10.2174/187152612800564455

4. Lobo EO, Zhang Z, Shively JE. Pivotal advance: CEACAM1 is a negative coreceptor for the B cell receptor and promotes CD19-mediated adhesion of B cells in a PI3K-dependent manner. J Leukoc Biol. (2009) 86:205-18. doi: 10.1189/jlb.0109037

5. Conde C, Gloire G, Piette J. Enzymatic and non-enzymatic activities of SHIP1 in signal transduction and cancer. Biochem Pharmacol. (2011) 82:1320-34. doi: 10.1016/j.bcp.2011.05.031

6. Zhang J, Somani AK, Siminovitch KA. Roles of the SHP-1 tyrosine phosphatase in the negative regulation of cell signalling. Semin Immunol. (2000) 12:361-78. doi: 10.1006/smim.2000.0223 recognize sialic acids (43). How ligand recognition regulates the functional activities of these inhibitory co-receptors is not yet clear (Table 2).

\section{CONCLUSIONS AND FUTURE PERSPECTIVE}

The inhibitory B cell co-receptors CD22, CD72, and Siglec$G$ regulate distinct $B$ cell functions: $C D 22$ regulates tonic signaling in conventional B cells, Siglec-G regulates B-1 cell homeostasis and CD72 regulates autoimmunity. Recognition of $\mathrm{Sm} / \mathrm{RNP}$ induces association of CD72 with BCR in B cells reactive to $\mathrm{Sm} / \mathrm{RNP}$ whereas recognition of $\alpha 2,3$ sialic acid induces association of Siglec-G with BCR in B-1 cells. Thus, different inhibitory co-receptors associate with BCR in distinct $\mathrm{B}$ cell populations depending on the ligand recognition of inhibitory co-receptors, thereby regulating distinct $\mathrm{B}$ cell functions, i.e., development of lupus-like disease by CD72 and B-1 cell homeostasis by Siglec-G. Recognition of endogenous ligands thus determines the $\mathrm{B}$ cell phenotypes regulated by CD72 and Siglec-G. Further determination of ligands of inhibitory co-receptors and elucidation of the roles of ligand recognition may advance our understandings on how inhibitory co-receptors regulate development and differentiation of B cells and suppress activation of pathological B cells. These studies may provide clues in understanding pathogenesis of immunological diseases.

\section{AUTHOR CONTRIBUTIONS}

TT conceived of this mini review and wrote the manuscript.

\section{ACKNOWLEDGMENTS}

I thank Dr. J.-Y. Wang (Fudan University) for critically reading the manuscript. The author's work was supported by JPSP Grantin-Aid for Scientific Research 26293062, 17H05790, 18 H02610.

7. Adachi T, Wienands J, Wakabayashi C, Yakura H, Reth M, Tsubata T. SHP-1 requires inhibitory co-receptors to down-modulate $\mathrm{B}$ cell antigen receptor-mediated phosphorylation of cellular substrates. J Biol Chem. (2001) 276:26648-55. doi: 10.1074/jbc.M100997200

8. Somani AK, Yuen K, Xu F, Zhang J, Branch DR, Siminovitch KA. The $\mathrm{SH} 2$ domain containing tyrosine phosphatase-1 down-regulates activation of Lyn and Lyn-induced tyrosine phosphorylation of the CD19 receptor in B cells. J Biol Chem. (2001) 276:1938-44. doi: 10.1074/jbc.M0068 20200

9. Dustin LB, Plas DR, Wong J, Hu YT, Soto C, Chan AC, et al. Expression of dominant-negative src-homology domain 2-containing protein tyrosine phosphatase-1 results in increased syk tyrosine kinase activity and B cell activation. J Immunol. (1999) 162:2717-24.

10. Nitschke L. CD22 and Siglec-G: B-cell inhibitory receptors with distinct functions. Immunol Rev. (2009) 230:128-43. doi: 10.1111/j.1600065X.2009.00801.x

11. Pao LI, Lam KP, Henderson JM, Kutok JL, Alimzhanov M, Nitschke L, et al. B cell-specific deletion of protein-tyrosine phosphatase Shp1 promotes B-1a cell 
development and causes systemic autoimmunity. Immunity (2007) 27:35-48. doi: 10.1016/j.immuni.2007.04.016

12. Maxwell MJ, Duan M, Armes JE, Anderson GP, Tarlinton DM, Hibbs ML. Genetic segregation of inflammatory lung disease and autoimmune disease severity in SHIP-1 $1^{-/-}$mice. J Immunol. (2011) 186:7164-75. doi: 10.4049/jimmunol.1004185

13. Yajima K, Nakamura A, Sugahara A, Takai T. FcgammaRIIB deficiency with Fas mutation is sufficient for the development of systemic autoimmune disease. Eur J Immunol. (2003) 33:1020-9. doi: 10.1002/eji.200323794

14. Nimmerjahn F, Ravetch JV. Fcgamma receptors as regulators of immune responses. Nat Rev Immunol. (2008) 8:34-47. doi: 10.1038/nri2206

15. Sato S, Miller AS, Inaoki M, Bock CB, Jansen PJ, Tang ML, et al. CD22 is both a positive and negative regulator of $\mathrm{B}$ lymphocyte antigen receptor signal transduction: altered signaling in CD22-deficient mice. Immunity (1996) 5:551-62. doi: 10.1016/s1074-7613(00)80270-8

16. Nitschke L, Carsetti R, Ocker B, Kohler G, Lamers MC. CD22 is a negative regulator of B-cell receptor signalling. Curr Biol. (1997) 7:133-43. doi: 10.1016/s0960-9822(06)00057-1

17. Otipoby KL, Andersson KB, Draves KE, Klaus SJ, Farr AG, Kerner JD, et al. CD22 regulates thymus-independent responses and the lifespan of B cells. Nature (1996) 384:634-7. doi: 10.1038/384634a0

18. Lamagna C, Hu Y, DeFranco AL, Lowell CA. B cell-specific loss of Lyn kinase leads to autoimmunity. I Immunol. (2014) 192:919-28. doi: 10.4049/jimmunol.1301979

19. Hoffmann A, Kerr S, Jellusova J, Zhang J, Weisel F, Wellmann U, et al. Siglec-G is a B1 cell-inhibitory receptor that controls expansion and calcium signaling of the B1 cell population. Nat Immunol. (2007) 8:695-704. doi: 10.1038/ni1480

20. Li DH, Winslow MM, Cao TM, Chen AH, Davis CR, Mellins ED, et al. Modulation of peripheral B cell tolerance by CD72 in a murine model. Arthritis Rheum. (2008) 58:3192-204. doi: 10.1002/art.23812

21. Xu M, Hou R, Sato-Hayashizaki A, Man R, Zhu C, Wakabayashi C, et al. $\mathrm{Cd} 72(\mathrm{c})$ is a modifier gene that regulates Fas(lpr)-induced autoimmune disease. J Immunol. (2013) 190:5436-45. doi: 10.4049/jimmunol.1203576

22. Wilkinson R, Lyons AB, Roberts D, Wong MX, Bartley PA, Jackson DE. Platelet endothelial cell adhesion molecule-1 (PECAM-1/CD31) acts as a regulator of B-cell development, B-cell antigen receptor (BCR)mediated activation, and autoimmune disease. Blood (2002) 100:184-93. doi: 10.1182/blood-2002-01-0027

23. Ujike A, Takeda K, Nakamura A, Ebihara S, Akiyama K, Takai T. Impaired dendritic cell maturation and increased $\mathrm{T}(\mathrm{H}) 2$ responses in PIR-B ${ }^{-/-}$mice. Nat Immunol. (2002) 3:542-8. doi: 10.1038/ni801

24. Yasuda S, Zhou Y, Wang Y, Yamamura M, Wang JY. A model integrating tonic and antigen-triggered BCR signals to predict the survival of primary B cells. Sci Rep. (2017) 7:14888. doi: 10.1038/s41598-017-13993-x

25. Pillai S, Cariappa A. The follicular versus marginal zone B lymphocyte cell fate decision. Nat Rev Immunol. (2009) 9:767-77. doi: 10.1038/nri2656

26. Jellusova J, Wellmann U, Amann K, Winkler TH, Nitschke L. CD22 x Siglec-G double-deficient mice have massively increased B1 cell numbers and develop systemic autoimmunity. I Immunol. (2010) 184:3618-27. doi: 10.4049/jimmunol.0902711

27. Takai T, Nakamura A, Endo S. Role of PIR-B in autoimmune glomerulonephritis. J Biomed Biotechnol. (2011) 2011:275302. doi: 10.1155/ 2011/275302

28. Muta T, Kurosaki T, Misulovin Z, Sanchez M, Nussenzweig MC, Ravetch JV. A 13-amino-acid motif in the cytoplasmic domain of Fc gamma RIIB modulates B-cell receptor signalling. Nature (1994) 368:70-3. doi: 10.1038/368 $070 \mathrm{a} 0$

29. Wernersson S, Karlsson MC, Dahlstrom J, Mattsson R, Verbeek JS, Heyman B. IgG-mediated enhancement of antibody responses is low in Fc receptor gamma chain-deficient mice and increased in Fc gamma RII-deficient mice. J Immunol. (1999) 163:618-22.
30. Brown MH, Lacey E. A ligand for CD5 is CD5. J Immunol. (2010) 185:6068-74. doi: 10.4049/jimmunol.0903823

31. Kumanogoh A, Watanabe C, Lee I, Wang X, Shi W, Araki H, et al. Identification of CD72 as a lymphocyte receptor for the class IV semaphorin CD100: a novel mechanism for regulating B cell signaling. Immunity (2000) 13:621-31. doi: 10.1016/s1074-7613(00)00062-5

32. Akatsu C, Shinagawa K, Numoto N, Liu Z, Ucar AK, Aslam M, et al. CD72 negatively regulates B lymphocyte responses to the lupus-related endogenous toll-like receptor 7 ligand Sm/RNP. J Exp Med. (2016) 213:2691706. doi: $10.1084 / \mathrm{jem} .20160560$

33. Lau CM, Broughton C, Tabor AS, Akira S, Flavell RA, Mamula MJ, et al. RNA-associated autoantigens activate B cells by combined B cell antigen receptor/toll-like receptor 7 engagement. J Exp Med. (2005) 202:1171-7. doi: $10.1084 /$ jem. 20050630

34. Christensen SR, Shupe J, Nickerson K, Kashgarian M, Flavell RA, Shlomchik MJ. Toll-like receptor 7 and TLR9 dictate autoantibody specificity and have opposing inflammatory and regulatory roles in a murine model of lupus. Immunity (2006) 25:417-28. doi: 10.1016/j.immuni.2006.07.013

35. Hutzler S, Ozgor L, Naito-Matsui Y, Klasener K, Winkler TH, Reth $\mathrm{M}$, et al. The ligand-binding domain of Siglec-G is crucial for its selective inhibitory function on B1 cells. J Immunol. (2014) 192:5406-14. doi: 10.4049/jimmunol.1302875

36. Macauley MS, Crocker PR, Paulson JC. Siglec-mediated regulation of immune cell function in disease. Nat Rev Immunol. (2014) 14:653-66. doi: $10.1038 /$ nri3737

37. Alborzian Deh Sheikh A, Akatsu C, Imamura A, Abdu-Allah HHM, Takematsu H, Ando $\mathrm{H}$, et al. Proximity labeling of cis-ligands of CD22/Siglec-2 reveals stepwise alpha2,6 sialic acid-dependent and independent interactions. Biochem Biophys Res Commun. (2018) 495:854-9. doi: 10.1016/j.bbrc.2017.11.086

38. Hennet T, Chui D, Paulson JC, Marth JD. Immune regulation by the ST6Gal sialyltransferase. Proc Natl Acad Sci USA. (1998) 95:4504-9. doi: 10.1073/pnas.95.8.4504

39. Collins BE, Smith BA, Bengtson P, Paulson JC. Ablation of CD22 in liganddeficient mice restores B cell receptor signaling. Nat Immunol. (2006) 7:199206. doi: $10.1038 /$ ni1283

40. Muller J, Obermeier I, Wohner M, Brandl C, Mrotzek S, Angermuller $\mathrm{S}$, et al. CD22 ligand-binding and signaling domains reciprocally regulate B-cell $\mathrm{Ca}^{2+}$ signaling. Proc Natl Acad Sci USA. (2013) 110:12402-7. doi: $10.1073 /$ pnas. 1304888110

41. Takai T. Paired immunoglobulin-like receptors and their MHC class I recognition. Immunology (2005) 115:433-40. doi: 10.1111/j.1365-2567. 2005.02177.x

42. Ho LH, Uehara T, Chen CC, Kubagawa H, Cooper MD. Constitutive tyrosine phosphorylation of the inhibitory paired Ig-like receptor PIR-B. Proc Natl Acad Sci USA. (1999) 96:15086-90. doi: 10.1073/pnas.96.26.15086

43. Kitazume S, Imamaki R, Ogawa K, Komi Y, Futakawa S, Kojima S, et al. Alpha2,6-sialic acid on platelet endothelial cell adhesion molecule (PECAM) regulates its homophilic interactions and downstream antiapoptotic signaling. J Biol Chem. (2010) 285:6515-21. doi: 10.1074/jbc.M109.073106

Conflict of Interest Statement: The author declares that the research was conducted in the absence of any commercial or financial relationships that could be construed as a potential conflict of interest.

Copyright $\odot 2018$ Tsubata. This is an open-access article distributed under the terms of the Creative Commons Attribution License (CC BY). The use, distribution or reproduction in other forums is permitted, provided the original author(s) and the copyright owner(s) are credited and that the original publication in this journal is cited, in accordance with accepted academic practice. No use, distribution or reproduction is permitted which does not comply with these terms. 